\title{
In Reply to "Diving Into Diagnostic Uncertainty: Strategies to Mitigate Cognitive Load. In Reference to: 'Focused Ethnography of Diagnosis in Academic Medical Centers'"
}

\author{
Vineet Chopra MD, MSc*, Sanjay Saint MD, MPH
}

Division of Hospital Medicine and the VA Ann Arbor Healthcare System, University of Michigan, Ann Arbor, Michigan

W e thank Dr. Santhosh and colleagues for their letter concerning our article. ${ }^{1}$ We agree that the diagnostic journey includes interactions both between and across teams, not just those within the patient's team. In an article currently in press in Diagnosis, we examine how systems and cognitive factors interact during the process of diagnosis. Specifically, we reported on how communication between consultants can be both a barrier and facilitator to the diagnostic process. ${ }^{2}$ We found that the frequency, quality, and pace of communication between and across inpatient teams and specialists are essential to timely diagnoses. As diagnostic errors remain a costly and morbid issue in the hospital setting, efforts to improve communication are clearly needed. ${ }^{3}$

Santhosh et al. raise an interesting point regarding cognitive load in evaluating diagnosis. Cognitive load is a multidimensional construct that represents the load that performing a specific task poses on a learner's cognitive system. ${ }^{4}$ Components often used for measuring load include (a) task characteristics such as format, complexity, and time pressure; (b) subject characteristics such as expertise level, age, and spatial abilities; and (c) mental load and effort that originate from the interaction between task and subject characteristics. ${ }^{5}$ While there is little doubt that measuring these constructs has face value in diagnosis, we know of no instruments that are nimble, straightforward, or suitable

Address for correspondence: Vineet Chopra MD, MSc; 2800 Plymouth Road Building 16, \#432W; Ann Arbor, Michigan 48109; Telephone: 734-936-4000; Fax: 734-832-4000; E-mail: vineetc@umich.edu

Received: July 17, 2018; Accepted: July 19, 2018

๑) 2018 Society of Hospital Medicine DOI 10.12788/jhm.3078 for such measurement in the clinical setting. Furthermore, unlike handoffs (which lend themselves to structured frameworks), diagnostic evolution occurs across multiple individuals (from attendings to house staff and students), specialties (from emergency physicians to medical and surgical specialists), and over time. A unifying framework and tool to measure cognitive load across these elements would not only be novel, but a welcomed and much-needed component to facilitate diagnostic efforts. We hope that our ethnographic work will spur the development of these types of instruments and highlight opportunities for implementation. A future that both measures cognitive load and targets interventions to reduce or balance these across members of the diagnostic team would be welcomed.

Disclosures: The authors have nothing to disclose.

Funding: This project was supported by grant number $\mathrm{P} 30 \mathrm{HSO} 24385$ from the Agency for Healthcare Research and Quality. The funding source played no role in study design, data acquisition, analysis or decision to report these data.

\section{References}

1. Chopra V, Harrod M, Winter S, et al. Focused ethnography of diagnosis in academic medical centers. J Hosp Med. 2018;13(10):668-672. doi: 10.12788/ jhm.2966

2. Gupta A, Harrod M, Quinn M, et al. Mind the overlap: how system problems contribute to cognitive failure and diagnostic errors. Diagnosis. 2018; In Press

3. Gupta A, Snyder A, Kachalia A, et al. Malpractice claims related to diagnostic errors in the hospital [published online ahead of print August 11, 2017]. BMJ Qual Saf. 2017. doi: 10.1136/bmjqs-2017-006774

4. Paas FG, Van Merrienboer JJ, Adam JJ. Measurement of cognitive load in instructional research. Percept Mot Skills. 1994;79(1 Pt 2):419-30. doi: 10.2466/ pms.1994.79.1.419

5. Paas FG, Tuovinen JE, Tabbers $H$, et al. Cognitive load measurement as a means to advance cognitive load theory. Educational Psychologist. 2003;38(1):63-71. doi: 10.1207/S15326985EP3801_8 